\title{
THE GENETIC BASIS OF PUPAL COLOUR DIMORPHISM AND ITS MAINTENANCE BY NATURAL SELECTION IN PAPILIO POLYXENES (PAPILIONIDAE: LEPIDOPTERA)
}

\author{
W. N. HAZEL \\ Department of Biology, Virginia Polytechnic Institute and State University, \\ Blacksburg, Virginia 24061
}

Received 12.x.76

\begin{abstract}
SUMMARY
The genetic basis of pupal colour dimorphism in the swallowtail Papilio polyxenes was studied by surveying the frequencies of brown and green pupae in broods from 23 wild caught females, and by selecting for production of brown and green pupae. It was concluded that the genetic basis of the dimoprhism is a threshold trait with quantitative genetic variation underlying the two phenotypes. It was further concluded that the dimorphism is maintained in nature by weak stabilising selection, thus explaining the occurrence of mismatches between pupal and background colour.
\end{abstract}

\section{INTRODUCTION}

THE genetic basis of environmentally controlled polymorphisms and their maintenance in nature by natural selection are poorly understood. Some of the best-known examples of environmentally controlled polymorphisms can be found among the Lepidoptera (Merrifield and Poulton, 1899; Clarke and Sheppard, 1972). In many species the larvae and the pupae are cryptically coloured and are distinctly dimorphic, being either green or brown with intermediates rare or absent. Each morph is particularly well adapted to a distinct type of background, and experiments have repeatedly shown the importance of crypsis to survival (Hidaka et al., 1959; Baker, 1970; Wiklund, 1975).

The environmental determinants of pupal colour in papilionid butterflies include the photoperiod under which the larvae are reared (West $e t$ al., 1972), the colour of the pupation substrate or the wavelengths of light to which the prepupa is exposed (Gardiner, 1974; Wiklund, 1972), and the texture and geometry of the substrate (West and Hazel, unpublished observations). In the multivoltine North American swallowtail Papilio polyxenes photoperiod during the late larval stages determines whether the ensuing pupa will be dimorphic (West et al., 1972). Autumn photoperiod causes an almost exclusive production of brown pupae, most of which enter diapause. Midsummer photoperiod permits the prepupa to respond to variation in the substrate with the appropriate pupal colour. It is the substrate experienced just before pupation that determines the pupal colour.

Pupal colour in Papilio xuthus and probably other closely related dimorphic species is controlled by an endocrine mechanism which causes the formation of a brown pupa only when activated by adequate environmental stimulation (Hidaka, 1961 $a, b$ ).

To investigate the genetic basis of the dimorphism in Papilio polytes Clarke and Sheppard (1972) conducted a selection experiment using back- 
ground matching and mismatching as the critcria for sclection. Rather than affecting the frequencies of matches and mismatches, however, selection caused in alteration of the pupation sites chosen by the larvae. The apparent reason for this was that in the population selected for mismatching, most of the selected pupae were green morphs on small brown twigs. Thus selection resulted in an increased tendency to choose brown twigs as pupation sites. In the population selected for background matching most of the selected pupae were green morphs on green backgrounds, and selection thus caused an increased tendency of the larvae to choose green pupation sites.

Although Clarke and Sheppard considered that mismatches were due to genetic variation in the amount of stimulus needed for the production of brown pupae, their selection programme was not designed along these lines. They selected for background matching and mismatching, instead of for the tendency to produce brown or green pupae. Since larvae were allowed to pupate on a variety of substrates and since pupal colour is a function of the intensity of the environmental stimuli and the genetic ability of the prepupal larva to interpret these stimuli and to respond with the appropriate pupal colour, then without control of the environmental stimuli (pupation site) the underlying genetic differences between individuals could not be discerned and selected upon. Thus, Clarke and Sheppard's results show that there is genetic variation in choice of pupation site, but they do not tell us anything about the genetic basis of pupal colour dimorphism.

Since the expression of the possible phenotypes of pupal colour is ultimately under the control of the environment, a thorough understanding of the environmental stimuli responsible for the expression of these phenotypes is necessary before any attempt can be made at investigating their genetic basis. Pupal colour dimorphism in Papilio polyxenes is an environmentally controlled polymorphism for which at least some of these environmental stimulj are known. The purpose of the present research on $P$. polyxenes was to determine the genetic variation between families in the ability to produce brown pupae, and through a selection experiment to determine how this variation is responsible for the dimorphism.

\section{Materials and methods}

(i) Rearing

Papilio polyxenes females were collected in Montgomery, Giles, and Augusta counties of western Virginia during the summer of 1975 . Within a few hours of capture they were placed in laying chambers consisting of cither a $14 \times 10 \mathrm{~cm}$ chromatography beaker or a $19 \times 20 \mathrm{~cm}$ plastic canister. In the former case the wings of the females were trimmed so that only a centimetre or so remained. Small pieces of wild carrot (Daucus carota) or fennel (Foeniculum vulgare) provided oviposition sites. The chambers were covered with cheese cloth and placed under constant warm bright light. The females were fed daily with sugar water and usually laid eggs readily.

Eggs were collected daily and placed in round plastic rearing dishes $(4 \times 15$ or $3 \times 11 \mathrm{~cm})$ with tight lids and filter paper liners. The larvae were reared in two Percival environmental chambers set for a 15-hour day and a 9-hour night. The day temperature was set at $27^{\circ} \mathrm{C}$ while the night temperature was set at $21^{\circ} \mathrm{C}$. During the early instars as many as 15 larvae 
could be reared in one large rearing dish without crowding. This number was quickly reduced as the larvae grew, so that by the fifth instar the larvae were maintained at one per dish. All first generation of laboratory reared larvae were fed fresh food plant, wild carrot or parsley, with the exception of broods number 22 and 23, which were reared on the artificial diet developed by Wiklund (1971) for Papilio machaon. The larvae were fed in abundance. Rearing dishes were sterilised in dilute sodium hypochlorite solution, usually every other day.

Just before pupation a fifth instar larva of Papilio polyxenes purges its gut of all digested and semi-digested food and begins a period of wandering to a pupation site. This period may last for several hours. Once a larva emptied its gut contents it was placed in a pupation chamber consisting of two sheets of Norton Tuf bak Durite type 1600 A black emery cloth taped together to form a $23 \times 20 \mathrm{~cm}$ cylinder, grit side facing inward. The emery cloth cylinder was then placed in a $19 \times 20 \mathrm{~cm}$ plastic canister and was topped with an additional piece of emery cloth, grit side down. Care was taken to avoid crowding the pupation chambers, which were placed in a Sherer environmental chamber set for a 15-hour day and a 9-hour night. The temperature was maintained at a constant $21^{\circ} \mathrm{C}$. After pupation the numbers of green and brown pupae formed on the emery cloth were recorded. The butterflies which eclosed were selectively hand paired after the method described by Clarke and Sheppard (1962). Females were then allowed to lay eggs and the larvae reared as previously described. All matings were between unrelated individuals, since inbreeding in $P$. polyxenes is known to cause severe egg and larval mortality (West and Hazel, unpublished observations).

\section{(ii) The selection programme}

Since all prepupal larvae were reared and tested in like environments, all differences in pupal colour were considered to be genetic in origin. Thus, individuals that responded with brown pupal colour were thought to be genetically more sensitive to stimulation from the pupation environment than those that responded with green pupal colour. Therefore, only adults eclosing from like-coloured pupae were paired. Offspring from brown $\times$ brown pairing were designated as the sensitive (brown) line, while offspring from green $\times$ green pairing were designated as the insensitive (green) line. The larvae produced from these matings were reared and tested as previously described, with the exception that the larvae were reared on the artificial diet developed by Wiklund (1971).

Unfortunately the selection programme had to be abandoned after only one generation due to an unusually high mortality from the use of the artificial food. Thus, of 37 successful pairings for the first generation of selection only five survived to pupation. These five lines survived because they were switched from artificial food to natural food around the third larval instar. Because of the use of the artificial food the numbers were so reduced by this time that only one more generation of selection could be conducted in the insensitive direction (green line) and no more selection in the sensitive direction (brown line). Other possible effects of the artificial diet will be considered in the discussion. 


\section{REsults}

(i) Analysis of genetic variation in the ability to produce brown pupae

Table 1 shows the sample size, number of brown pupae, number of intermediate pupae, the percentage of brown pupae, and the transformed percentage of brown pupae produced per brood for all 23 broods tested.

TABLE 1

Number of brown pupae, sample size, percentage brown pupae and transformed percentage brown pupae produced for 23 broods pupating in controlled conditions

$\begin{array}{cccccc}\text { Brood } & \begin{array}{c}\text { Number } \\ \text { brown }\end{array} & & \begin{array}{c}\text { Sample } \\ \text { size }\end{array} & \begin{array}{c}\text { Percentage } \\ \text { brown }\end{array} & \begin{array}{c}\text { Transformed } \\ \text { percentage } \\ \text { brown }\end{array} \\ 1 & 5 & & 15 & 33 \cdot 3 & 35 \cdot 87 \\ 2 & 1 & & 7 & 14 \cdot 3 & 25 \cdot 35 \\ 3 & 3 & & 51 & 5 \cdot 9 & 14 \cdot 06 \\ 4 & 8 & 6^{*} & 49 & 16 \cdot 3 & 24 \cdot 34 \\ 5 & 6 & & 46 & 13 \cdot 0 & 21 \cdot 82 \\ 6 & 13 & & 48 & 27 \cdot 1 & 31 \cdot 66 \\ 7 & 6 & & 32 & 18 \cdot 2 & 26 \cdot 33 \\ 8 & 23 & 1^{*} & 52 & 44 \cdot 2 & 41 \cdot 67 \\ 9 & 25 & & 43 & 58 \cdot 1 & 49 \cdot 58 \\ 10 & 4 & & 24 & 16 \cdot 7 & 25 \cdot 07 \\ 11 & 2 & 1^{*} & 20 & 10 \cdot 0 & 20 \cdot 09 \\ 12 & 14 & & 32 & 43 \cdot 7 & 41 \cdot 52 \\ 13 & 12 & 1^{*} & 26 & 46 \cdot 2 & 42 \cdot 87 \\ 14 & 8 & & 27 & 29 \cdot 6 & 33 \cdot 42 \\ 15 & 3 & 1^{*} & 21 & 14 \cdot 3 & 23 \cdot 46 \\ 16 & 3 & & 12 & 25 \cdot 0 & 31 \cdot 20 \\ 17 & 7 & 1^{*} & 27 & 25 \cdot 9 & 31 \cdot 16 \\ 18 & 5 & & 24 & 20 \cdot 8 & 27 \cdot 95 \\ 19 & 13 & & 66 & 19 \cdot 7 & 26 \cdot 35 \\ 20 & 11 & & 20 & 55 \cdot 0 & 47 \cdot 74 \\ 21 & 5 & & 15 & 33 \cdot 3 & 35 \cdot 87 \\ 22 & 8 & & 10 & 80 \cdot 0 & 61 \cdot 64 \\ 23 & 5 & & 12 & 41 \cdot 7 & 40 \cdot 56 \\ & & & & & \\ \text { Totals } & 190 & 11 * & 679 & 27 \cdot 9 & \end{array}$

Mean transformed percentage brown $=33.03$

* Intermediate colour.

Transformations were made by the method of Mosteller and Youtz (1961) for sample sizes less than 50 and by the angular transformation for sample sizes greater than 50 to stabilise the variance (Sokal and Rohlf, 1969). Also shown are the total number of pupae tested, and the overall percentage of brown pupae tested, and the overall percentage of brown pupae produced. The average transformed percentage of brown pupae per brood was 33.03. The transformed data were tested for goodness of fit against a normal distribution using the Kolmogorov statistic (Stephens, 1974) and were found not to differ significantly from the normal $(P>0 \cdot 225)$. The transformed data, displaycd in fig. 1 as a histogram, show a distribution with one mode and two tails. 


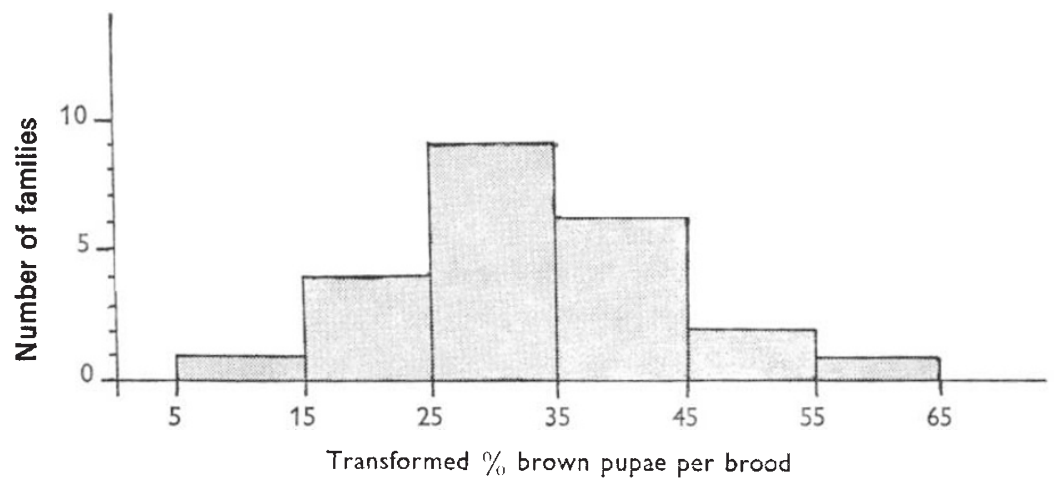

FIG. 1.-Distribution of sensitivities in a natural population of Papilio polyxenes plotted as a histogram.

(ii) Analysis of the results of the selection programme

Selected line and midparent values for the percentage of brown pupae produced in both lines are shown in table 2 for the first, and in table 3 for the second, generations of selection. Thus from table 2 , in brood $9 \times 10$ of

TABLE 2

The response to selection in the first generation

Pairing $\overbrace{\begin{array}{c}\text { Percentage } \\ \text { brown }\end{array}}^{\text {Midparent values }} \overbrace{\begin{array}{c}\text { Sample } \\ \text { size }\end{array}}^{\text {Percentage } \begin{array}{c}\text { Sample } \\ \text { brown }\end{array} \text { size }}$,

A. The insensitive (green) line

$\begin{array}{rrrrr}14 \times 15 & 23.4 & 47 & 54.5 & 66 \\ 9 \times 10 & 43.3 & 67 & 41 \cdot 7 & 12\end{array}$

B. The sensitive (brown) line

$\begin{array}{rrrrr}14 \times 15 & 23.4 & 47 & 65.6 & 32 \\ 3 \times 4 & 11.7 & 94 & 71 \cdot 4 & 7 \\ 22 \times 23 & 59.1 & 22 & 92.9 & 14\end{array}$

TABLE 3

The response of the insensitive (green) line to selection in the second generation

\begin{tabular}{|c|c|c|c|c|}
\hline \multirow[b]{2}{*}{ Pairing } & \multicolumn{2}{|c|}{ Midparent values } & \multicolumn{2}{|c|}{ Selected line values } \\
\hline & $\begin{array}{c}\text { Percentage } \\
\text { brown }\end{array}$ & $\begin{array}{c}\text { Sample } \\
\text { size }\end{array}$ & $\begin{array}{c}\text { Percentage } \\
\text { brown }\end{array}$ & $\begin{array}{l}\text { Sample } \\
\text { size }\end{array}$ \\
\hline$(14 \times 15) \times(9 \times 10) A$ & $52 \cdot 6$ & 78 & $11 \cdot 8$ & 71 \\
\hline$(14 \times 15) \times(9 \times 10) B$ & $52 \cdot 6$ & 78 & $21 \cdot 7$ & 23 \\
\hline$(14 \times 15) \times(9 \times 10) C$ & $52 \cdot 6$ & 78 & $45 \cdot 4$ & 11 \\
\hline
\end{tabular}

the insensitive (green) line, adults eclosing from green pupae in broods 9 and 10 were hand paired. The total percentage of brown pupae produced in broods 9 and 10 was 43.3 per cent; this is the midparent value for brood $9 \times 10$. The percentage of brown pupae produced in brood $9 \times 10 \mathrm{com}-$ prises the selected line value. In the second generation of selection in the 
insensitive (green) line three replicate pairings were made between individuals of the two selected first generation broods. These pairings were designated $(14 \times 15) \times(9 \times 10) \mathrm{A}, \mathrm{B}$ and $\mathrm{G}$ (table 3$)$.

The numbers of green and brown pupae produced in the selected lines were tested for independence against the numbers of green and brown pupac produced in the parental broods using the G-statistic. The results of this test, the intensity of selection, and the direction of the response to selection for each pairing are shown for both generations of selection in table 4 . Thus, in brood $9 \times 10$ in the insensitive line 57 per cent of the pupae

\section{TABle 4}

The intensity of selection, direction and $G$-test of the response to selection

\begin{tabular}{|c|c|c|c|}
\hline $\begin{array}{c}\text { Pairing } \\
\text { The furst generation }\end{array}$ & Intensity $(\%)$ & Direction & G-test \\
\hline \multicolumn{4}{|c|}{ The insensitive (green) line } \\
\hline $\begin{array}{r}14 \times 15 \\
9 \times 10\end{array}$ & $\begin{array}{l}77 \\
57\end{array}$ & $\begin{array}{l}\text { Brown } \\
\text { Green }\end{array}$ & $\begin{array}{c}\mathrm{P}<0.005 \\
\text { n.s. }\end{array}$ \\
\hline \multicolumn{4}{|c|}{ The sensitive (brown) line } \\
\hline $\begin{array}{r}14 \times 15 \\
3 \times 4 \\
22 \times 23\end{array}$ & $\begin{array}{l}23 \\
12 \\
59\end{array}$ & $\begin{array}{l}\text { Brown } \\
\text { Brown } \\
\text { Brown }\end{array}$ & $\begin{array}{l}P<0.005 \\
P<0.005 \\
P<0.005\end{array}$ \\
\hline
\end{tabular}

The second generation

The insensitive (green) line

$\begin{array}{cccc}(14 \times 15) \times(9 \times 10) \mathrm{A} & 47 & \text { Green } & \mathrm{P}<0.005 \\ (14 \times 15) \times(9 \times 10) \mathrm{B} & 47 & \text { Green } & \mathrm{P}<0.005 \\ (14 \times 15) \times(9 \times 10) \mathrm{C} & 47 & \text { Green } & \text { n.s. }\end{array}$

produced in the two parental broods were green, giving a 57 per cent intensity of selection. From this pairing a non-significant increase in the frequency of the green morph was produced in the next generation, and thus the response in this pairing was in the insensitive direction.

\section{Discussion and conclusions}

The genetic basis of the pupal colour dimorphism in Papilio polyxenes can best be explained by considering the production of brown pupal colour as a threshold trait (Falconer, 1965). If this were the case one would expect additive genetic variation around some population mean in the ability to produce a brown pupa, a trait that will be designated sensitivity. At some point in this scale of variation there is a threshold so that all individuals on one side, the sensitive side, of the threshold will be brown, while those individuals on the other side, the insensitive side, will produce green pupae. It should be noted that the threshold in an immovable point in the distribution of genetic sensitivities, separating a continous distribution of genotypes into two discretc phenotypes. The data presented in this paper support this hypothesis.

The results from the 23 different broods reared and tested under uniform conditions indicate that there is considerable genetic variation in the mechanism responsible for the production of brown pupae in this species. Since sperm precedence is probably the case in this species (Clarke and 
Sheppard, 1962), in that the spermatophore from the last mating provides the sperm for all later fertilisations, the 23 broods sampled here represent a sampling of 46 haploid genomes. Thus, the percentage of brown pupae produced in each brood provides a measure of the average sensitivity of the two parents to the environmental stimuli responsible for brown pupal colour. If the percentage of brown pupae formed in each brood is transformed, to stabilise the variance, one can then obtain an estimate of the mean sensitivity of the population, which in this case was 33.03, this being the arithmetic mean of the transformed percentage of brown pupae produced in each brood. Superimposed on this distribution of genotypes are two phenotypes. Of the 679 larvae from 23 broods, 190, or approximately 28 per cent, produced brown pupae. This would place the threshold at some point to the sensitive side of the mean so that all individuals to the sensitive side of the threshold make up the 28 per cent of individuals having brown pupal colour.

There must also be additive genetic variation within broods, hence the lack of uniformity in pupal colour within any brood. For example, brood number 3 was the least sensitive of the broods tested, producing approximately 6 per cent brown pupae. This would place it to the insensitive side of the population mean; yet there was still sufficient genetic variation within this brood for three individuals to be on the sensitive side of the threshold. Therefore, the data indicate that there is quantitative genetic variation within and among broods in sensitivity to the environmental stimuli responsible for the formation of brown pupae.

The results of the selection programme seem to indicate that the difference between broods is at least partly genetic, and that it forms the basis for the two pupal colour phenotypes.

Since seven of the eight selected lines responded in the direction predicted by the threshold hypothesis, and since five of these seven lines responded significantly $(\mathrm{P}<0 \cdot 005)$, the threshold hypothesis seems to be the best explanation for the genetic basis of pupal colour dimorphism in this species.

The response of a threshold trait to selection will depend on the position of the threshold relative to the direction of selection. Since the position of the threshold controls the intensity with which one may select, it follows that the response of a threshold trait to selection in generation $\mathrm{N}$ will ultimately affect the intensity with which one may select in generation $\mathrm{N}+1$. The results of selection in the green line illustrate this nicely. Broods 14 and 15 had a total of 77 per cent green pupae. Therefore, the selected individuals were taken out of the bottom 77 per cent of the brood on the scale of sensitivity. The response to selection of the green line pairing from these broods was significant $(\mathrm{P}<0 \cdot 005)$, but in the wrong direction. This response can be explained by the fact that a 77 per cent truncation for selection means that 27 per cent of those individuals that had a possibility of being selected to pair for the next generation lay on the sensitive side of the mean. If by chance two such individuals were selected for the pairing and if the trait were highly heritable, then a significant response in the sensitive direction could be expected. I feel that the results of selection pairing $14 \times 15$ do not represent a contradiction of the threshold hypothesis for the following reasons: (i) all other pairings responded in the direction predicted by the threshold hypothesis, (ii) the 77 per cent truncation for selection in this line was the highest of all lines selected, thus the intensity 
of selection in this line was lowest of all selected pairings, and (iii) data from other selected lines indicate that this trait is quite heritable.

The result of the response of pairing $14 \times 15$ to selection was to increase the intensity of selection in the next generation so that the truncation for selection was 47 per cent. Thus, in the second generation of selection in the insensitive direction two of the three replicate pairings moved significantly $(\mathrm{P}<0.005)$ in the direction predicted by the threshold hypothesis, and the third non-significantly in the same direction.

The pairings in the brown line experienced the most intense selection. As a result, all brown lines responded significantly to selection $(\mathrm{P}<0.005)$, and in the predicted direction.

Although the use of the artificial diet did reduce the numbers it seems doubtful that this had any effect on the outcome of the selection experiment. Rothschild et al. (1975) have reported a lack of response to background colour in Pieris brassicae pupae reared on a carotenoid-free diet. The effects of the artificial diet on pupae of Papilio polyxenes were two-fold. Those pupae that would have normally been considered green were turquoise blue, and most pupae had severely deformed wing pads. Nevertheless, the artificial diet did not seem to have an effect on the ability of pupae to modify their colour. Switching the larvae from artificial food to natural food at around the third or fourth instar appeared to reverse the effects of the artificial diet completely, so that normally coloured pupae were formed with no developmental difficulties. For this reason the effect of the artificial diet on the selection would be small or non-existent, unless the mortality was nonrandom with respect to sensitivity.

The effects of natural selection on a genetic system of the sort presented will be two-fold. First, selection will be stabilising by eliminating those individuals that are extremely sensitive or insensitive to environmental stimulation. Extremely sensitive prepupae will produce brown pupae with very little environmental stimulation, even on green surfaces. Extremely insensitive prepupac will produce green pupae even with stimulation that would normally be adequate for the production of brown pupae. Pupae of this type will tend to be green on brown backgrounds. Thus natural selection on the basis of background matching will be stabilising by eliminating individuals from the tails of the sensitivity distribution. Second, because of the nature of the trait, selection cannot eliminate the genetic variation in sensitivity. Since selection will be on the basis of background matching it may sometimes favour the extremely sensitive and extremely insensitive extremes of the distribution of sensitivities. The following example will clarify this point. Although an extremely sensitive prepupa will have a high probability of producing a brown pupa regardless of the substrate, in cases where it pupates on a brown surface it will still match its background and be selected for. The same will hold true for extremely insensitive prepupa. If an insensitive prepupae pupates on a green surface it will be selected for since it will still match its background. Thus, natural selection on the basis of background matching will tend to stabilise the sensitivity distribution at the optinum level for the habitat, while at the same time maintaining genetic variation in the sensitivity of prepupal larvae, therefore, the occurrence of mismatches.

Clarke and Sheppard (1972) have reasonably suggested that a green pupa on a brown background may be more cryptic than a brown pupa on 
a green background. My data give no indication of skewness in the distribution of sensitivities, although the sample size is small.

Clarke and Sheppard (1972) have also suggested that apostatic selection may play a part in maintaining genetic variation in pupal colour dimorphism. In Papilio polyxenes, females lay eggs singly and the larvae are dispersed. I have only found larvae of this species on rare occasions and have never found a pupa in the field, even though I visited the habitat twice daily during the summer. Since apostatic selection is a form of density-dependent selection, in that without a high density of prey species of one morph a hunting image cannot be formed, it seems unlikely that apostatic selection is an important selective force operating on the pupal colour dimorphism in a widely dispersed species like Papilio polyxenes, although it may be important in a gregarious species like Battus philenor.

Pupal colour in the machaon group of swallowtails (Papilio machaon, $P$. polyxenes, $P$. xuthus, and others) presents an interesting evolutionary problem. In this group the life history of a species plays a large part in determining whether or not it will be dimorphic. Thus in the multivoltine species, $P$. polyxenes and $P$. xuthus, short photoperiod has an overriding effect on all other stimuli so that nearly all pupae enter diapause and are monomorphic (brown in $P$. polyxenes, orange in P. xuthus) (Ishizaki and Kato, 1959; West et al., 1972), while in P. machaon in Great Britain where it is usually univoltine, larvae rarely experience short photoperiods and most pupae are diapausing and dimorphic (Gardiner, 1974). It is possible that the overriding effect of photoperiod on the dimorphism is a newly evolved trait in the multivoltine members of this group and that the selective advantage of the dimorphism may be different in the diapausing generations of multivoltine and univoltine members of this group.

Baker (1972) found in the pupae of Pieris rapae that selection acted both on the choice of pupation site and on the matching between pupal colour and background colour. Clarke and Sheppard (1972) have shown in Papilio polytes, a dimorphic species, that there is genetic variation in choice of pupation site and that this variation can be selected upon, resulting in an alteration in the choice of pupation site. The data presented here show that there is genetic variation in the ability to modify pupal colour in Papilio polyxenes. Clarke and Sheppard (1972) have also suggested that in those species where the pupation site chosen by a larva is not correlated with that chosen by its parents, selection will tend to favour the evolution of pupal colour dimorphism. It therefore follows that there should be little additive genetic variation in the choice of a pupation site in a monomorphic species such as Papilio glaucus, since there should be a correlation in choice of pupation site from parent to offspring, and since strong selection should operate on the choice of a pupation site.

Acknowledgments.--The author would like to thank William J. Thompson for assistance in rearing the laboratory populations, and Walter Pirie for consultation on the statistical analysis. I wish also to express my appreciation to David A. West for his comments of encouragement in this research.

\section{REFERENCES}

BAKER, R. R. 1970. Bird predation as a selective pressure on the immature stages of the cabbage butterflies. Pieris rapae and P. brassicae. 7. Zool., Lond., 152, 43-59. 
CLARKE, C. A., AND SHEPPARD, P. M. 1962. Offspring from double matings in swallowtail butterflics. The Entomologist, August.

CLARKE, C. A., AND SHEPPARD, P. M. 1972. Genetic and environmental factors influencing pupal colour in the swallowtail butterflies Battus philenor (L.) and Papilio polytes L. 7. Entomol. $(A), 46,123-133$.

FAICONER, D. s. 1965. The inheritance of liability to certain diseases, estimated from the incidence among relatives. Ann. Hum. Genet., Lond., 29, 51-71.

GARDINER, B. o. C. 1974. Observations on green pupae in Papilio machaon L. and Pieris brassicae L. Wilhelm Roux Archiv., 176, 13-22.

HIDAKA, T., KIMURA, T., AND ONOSAKA, M. 1959. Expcriments on the protective coloration of pupae of the swallowtail, Papilio xuthus L. (In Japanese with English summary.) Dobutsukaku zasshi, 68, 222-226.

HIDAKA, T. 1961a. Mis en evidence de l'activité secretoire du ganglion prothoracique dans l'adaptation de la nymphe du Papilio xuthus L. C.r. Soc. Biol., Paris, 154, 16821685.

HIDAKA, T. 1961 b. Recherches sur le mecanisme endocrine de l'adaptation chromatique morphologique chez les nymphs de Papilio xuthus L. Tokyo Daigaku. Rigabuky. 7. fac. Sci. Imp. Univ. Tokyo, Scct. IV, 9, 223-261.

MERRIFIELD, F., AND POULTON, E. B. 1899. The colour-relation betwecn the pupae of Papilio machaon, Pieris napi and many other species, and the surroundings of the larvae preparing to pupate, etc. Trans. Ent. Soc., Lond., 1988, 369-433.

MOSTELleE, F., AND YOUTZ, c. 1961. Tables for the Freeman-Tukey transformations for the binomial and Poisson distributions. Biometrika, 48, 433,440.

ROTHSCHILD, M., GARDINER, B., VALADON, G., AND MUMMERY, R. 1975. Lack of response to background colour in Pieris brassicae pupae reared on carotenoid-free diet. Nature, $254,592-594$.

SOKAL, R. R., AND ROHLF, F. J. 1969. Statistical Tables. W. H. Freeman and Company, San Francisco.

STEPHENS, M. A. 1974. EDF statistics for goodness of fit and some comparisons. 7. Am. Stat. Ass., 19 (No. 347), 703-737.

WEST, D. A., SNELlings, w. M., AND HERBEK, T. A. 1972. Pupal color dimorphism and its environmental control in Papilio polyxenes asterius Stoll (Lepidoptera: Papilionidae). 7. New Tork Ent. Soc., 80 (No. 4), 205-211.

WIKLUND, C. 1971. Inonhusodling av Makaonfjärilen. (In Swedish with English summary). Zool. Revy, 33 (1-2), 1971, 35-42.

wIKLund, c. 1972. Pupal coloration in Papilio machaon in response to the wavelength of light. Naturwissenschaflen, 59, 219.

Wiklund, c. 1975. Pupal colour polymorphism and the survival in the field of cryptic versus non-cryptic pupae in Papilio machaon L. 7. Royl Ent. Soc., 127, 73-84. 